\title{
$\underline{\mathbf{P}-169}$
}

\section{Ethnobotanical Study of Medicinal Plants Utilized by Tribal Communities at Ramghat (Western Ghats), Maharastra, India}

\author{
Rajarajeshwari $\mathrm{N}^{1, *}$, Parixit Bhandurge ${ }^{1}$, Ganapaty $\mathrm{S}^{1}$, Namita $\mathrm{N}^{2}$ and Santosh Pattanshetti ${ }^{1}$ \\ ${ }^{I}$ Dept of Pharmacognosy and Phytochemistry, Visveshwarapura Institute of Pharmaceutical Sciences, Banashankri II, \\ Bangalore - 560070, India; ${ }^{2}$ Dept of Pharmacognosy and Phytochemistry, University College of Pharmaceutical \\ Sciences, Andhra University, Visakhapatnam -530003,India; E-mail:vipsraju@gmail.com
}

Ethnopharmacological relevance: This study presents the rich resource of medicinal plants used by the tribes of Ramghat region of Western Ghats (Maharastra, India). It was aimed to identify the important species used in the management of human health and at establishing the plant parts used and the mode of preparation of remedies. These plants create a basis for phytochemical evaluation which can lead to the discovery of biologically active compounds.

Methodology or Material and methods: A total of 11 local herbal practitioners from Ramghat Region (10 men and 1 woman) were interviewed using specimen display method and a Field-Walk through the areas. A semistructured questionnaire was designed to elicit the knowledge of use of medicinal plants.

Result: The present study has resulted in the documentation of 141 medicinal plant species used by the tribals. These medicinal plant species were distributed across 56 families and 108 genera. Ebnaceae was the most dominant family (12 species, 1 genus) of medicinal plants, followed by Fabaceae (11 species, 7 genera), Orchidaceae ( 7 species, 6 genera), Liliaceae ( 7 species, 4 genera) and Apocynaceae (6 species, 4 genera). Leaves (23.5\%) constituted the major plant part used for treatment of ailments, followed by underground parts (roots, rhizomes, bulbs, tubers) $(22.5 \%)$, and fruits $(11 \%)$. Common ailments like various types of fevers, gastrointestinal disorders, sexual problems, respiratory tract diseases, and skeletal problems (inflammation, bone fractures etc.) were mostly treated. Other more complicated disorders treated by the traditional practitioners included cardiovascular disorders, hepatic disorders, and diabetes.

Conclusion: From the study it is clear that ethnomedicinal information from traditional practitioners provides substantial basis for selection of plants towards development of lead compounds or newer drugs.

Keywords: Ramghat, Ethnobotanical survey, Traditional herbal knowledge. 